Those children who survive this massive insult, however, seem to make a complete clinical recovery. All survivors were leading a normal life within four weeks of discharge from hospital. Nevertheless, liver biopsy specimens from most survivors in the King's study showed appreciable inflammatory change, sufficient to warrant a histological diagnosis of chronic aggressive hepatitis. Subsequent repeat specimens showed postnecrotic scarring. Adult survivors normally show rapid and complete histological recovery. ${ }^{12}$

Clearly children with such a severe and complex disease should be managed in specialised units. Only in this way will survival be improved in this potentially treatable disease. Transfer of very sick patients over large distances may be a problem; they should be accompanied by a doctor and a nurse, and on the journey intravenous fluids should be carefully controlled, giving high concentrations of glucose to prevent hypoglycaemia and limiting excessive sodium and water intake.

1 Psacharopoulos HT, Mowat AP, Davies M, Portmann B, Silk DBA, Williams R. Fulminant hepatic failure in childhood. Arch Dis Child $1980 ; 55: 252-8$.

${ }^{2}$ Clark R, Rake MO, Flute PT, Williams R. Coagulation abnormalities in acute liver failure; pathogenetic and therapeutic implications. Scand $\mathcal{f}$ Gastroenterol 1973;19, suppl 8:63-70.

${ }^{3}$ Miller DJ, Saunders SJ, Hickman R, Terblanche J. Acute hepatic necrosis: a review of causes and management of fulminant hepatic failure. In: Read AE, ed. Modern trends in gastroenterology-5. London: Butterworth, $1975: 64-90$.

4 Wilkinson SP, Gazzard BG, Arroyo V, Moodie H, Williams R. Relation of renal impairment and haemorrhagic diathesis to endotoxaemia in fulminant hepatic failure. Lancet 1974 ; : $: 521-4$

5 Bailey RJ, Woolf IL, Cullens H, Williams R. Metabolic inhibition of polymorphonuclear leucocytes in fulminant hepatic failure. Lancet 1976;i:1162-3.

6 Shaywitz BA, Leventhal JM, Kramer MS, Venes JL. Prolonged continuous monitoring of intracranial pressure in severe Reye's syndrome. Pediatrics 1977;59:595-605.

${ }^{7}$ MacDougall BRD, Bailey RJ, Williams $\mathrm{R} . \mathrm{H}_{2}$-receptor antagonists and antacids in the prevention of acute gastrointestinal haemorrhage in fulminant hepatic failure. Two controlled trials. Lancet 1977;i :617-9.

${ }^{8}$ European Association for the Study of the Liver (EASL). Randomised trial of steroid therapy for acute liver failure. Gut $1979 ; 20: 620-3$.

${ }^{9}$ Denis J, Opolon P, Nusinovici V, Granger A, Darnis F. Treatment of encephalopathy during fulminant hepatic failure by haemodialysis with high permeability membrane. Gut 1978;19:787-93.

10 Saunders SJ, Seggie J, Kirsch RE, Terblanche J. Acute liver failure. In: Wright R, et al, eds. Liver and biliary disease. London: WB Saunders, 1979:569-84.

11 Trey C, Lipworth, L, Davidson CS. Parameters influencing survival in the first 318 patients reported to the Fulminant Hepatic Failure Surveillance Study. Gastroenterology 1970;58:306.

12 Karvountzis GG, Redeker AG, Peters RL. Long term follow-up studies of patients surviving fulminant viral hepatitis. Gastroenterology 1974; $67: 870-7$.

\section{The prognosis of multiple sclerosis}

Multiple sclerosis is the most common neurological disease affecting young adults in temperate climates. ${ }^{1}$ Despite the tremendous variability of its symptoms, clinicians naturally try to give their patients guidance on their prospects for continued employment and independence, the need for family and community support, and the eventual course of the disease. A truly prospective study applied to such a diverse disorder is seldom feasible ${ }^{2}$; and to be of value retrospective data need to adhere to strict criteria, conforming where possible with earlier studies. In particular, the retrospective approach carries a risk that milder cases may be overlooked. Case reports need to be eliminated where the information is sparse, and recent and more refined diagnostic methods such as visual evoked potentials may not have been used. Moreover, whatever the diagnostic approach, epidemiological studies need to take account of the clinically silent cases that may be discovered at necropsy. ${ }^{3}$

McAlpine's classic review ${ }^{2}$ has now been reinforced by a computer-processed analysis of 349 patients collected from 1957 to 1976 and followed up for an average of nine years at the neurological centre in Lyon. ${ }^{5}$ The main lesson of these actuarial data is that multiple sclerosis may be regarded as a single entity. Around $70 \%$ of patients who develop the disease do so between 20 and 40 years of age. Typically, the onset is at 30 with complete remissions; by the age of 34 the remissions begin to leave residual disability, and at 38 years the progressive phase sets in. These are mean ages and the standard deviation is 10 years. In the Lyon series $18 \%$ of patients showed progressive deterioration from onset.

Where early remissions are succeeded by a progressive phase the shorter the interval between the first two relapses the sooner the progressive phase appears. In the period before the progressive phase begins the frequency of relapses and the proportion of the relapses affecting the sensory and motor tracts and cerebellar system tend to increase while the proportion affecting the cranial and optic nerves decreases. At one time ${ }^{2}$ sensory symptoms and symptoms relating to the cranial nerves and visual pathways were thought to remit more readily and carry a more favourable prognosis than motor or cerebellar symptoms, but Confavreux $e t a l^{5}$ conclude that the relative risks of producing lasting sequelae or triggering the progressive phase depend anatomically on the space occupied by these systems in the neuraxis.

Of the 349 patients in the French study, 140 were men and 209 women. ${ }^{5}$ The men had a lower mean age of onset, but other studies have shown an opposite trend ${ }^{6}{ }^{7}$-and the sex of the patient has no prognostic value. The sample proved too small for prognostic analysis of histocompatibility antigens, and no correlation was found between the cell count or total protein concentration in the cerebrospinal fluid and the eventual outcome. Increases in gammaglobulin concentration and in the ratio of gammaglobulin to total protein seemed to be more closely related to the age distribution of the patients than to prognosis.

The degree of disability was assessed on the McAlpine scale $^{2}$ as: no disability (grades 0-1), moderate disability (still ambulatory, grades 2-3), and severe disability (non-ambulatory, grades 4-6). There was a strong correlation of the age of onset with the interval to moderate disability: this interval averaged eight years in the youngest patients with age of onset at 20 but only one year in patients aged 50 at onset. Severe disability developed after 14.3 years in the young and after 4.8 years in the older patients. Ten per cent died within 15 years, and this suggests a mean survival time of around 30 years.

The disability score and duration of the disease were combined to define various forms of the disease. Patients with benign forms ${ }^{6} 8$ (constituting $14 \%$ of all patients) show no disability after 10 years and moderate disability after 15 years. Whereas McAlpine ${ }^{6}$ found a low relapse rate in the second year, Confavreux et $a l^{5}$ commented that the number of relapses in the remittent phase had an interesting relation to outcome, the "benign" forms having a greater number of relapses. In contrast, patients with the "hyperacute" form $(8 \%$ of the total) were severely disabled within less than five years. Hyperacute forms were three times more common in 
patients with a progressive than those with a remittent onset. Overall, a late onset of the disease, a short interval between the first two relapses, and the occurrence of the progressive phase were all associated with a poor outcome.

${ }^{1}$ Millar JHD. Multiple sclerosis: introduction. Br Med Bull 1977;33:1-3.

${ }_{2}$ McAlpine D. Course and prognosis. In: McAlpine D, Lumsden CE, Acheson ED, eds. Multiple sclerosis: a reappraisal. 2nd ed. London: Churchill, 1972:197-223.

${ }^{3}$ Georgi W. Multiple sclerose : pathologisch-anatomische Befunde multipler sklerose bei klinisch nicht diagnostizierten Krankheiten. Schweiz Med Wochenschr 1961 ;91:605-7.

4 Mackay RP, Hirano A. Forms of benign multiple sclerosis. Report of two "clinically silent" cases discovered at autopsy. Arch Neurol 1967;17: $588-600$.

5 Confavreux C, Aimard G, Devic M. Course and prognosis of multiple sclerosis assessed by the computerized data processing of 349 patients. Brain 1980;103:281-300.

${ }^{6}$ McAlpine D. The benign form of multiple sclerosis. A study based on 241 cases seen within three years of onset and followed up until the tenth year or more of the disease. Brain 1961;84:186-203.

${ }^{7}$ Leibowitz U, Alter M. Multiple sclerosis. Clues to its cause. Amsterdam: North Holland Publishing Company, 1973.

${ }^{8}$ Anonymous. Benign type of disseminated sclerosis. $\mathrm{Br} \mathrm{Med} \mathcal{F}$ 1962; ; :780.

\section{BCG in Britain}

Tuberculosis is almost always transmitted by the airborne route. In Britain today chemotherapy is the most successful tactic used against this mode of spread, rapidly rendering patients whose sputum contains Mycobacterium tuberculosis non-infectious. Chemotherapy may be backed by chemoprophylaxis in those infected (tuberculin positive without prior BCG vaccination) but disease free, thus reducing the numbers later becoming infectious to others. For specific prophylaxis vaccination with BCG is offered to certain groups of people who have not been infected naturally. These groups include contacts of active cases, 10-13-year-old schoolchildren, and those at high risk of infection such as some hospital personnel. Is this use of BCG reasonable?

The effectiveness of BCG vaccination in British schoolchildren is not in doubt. In the controlled trial organised by the Medical Research Council in 1950-2 vaccination led to a $77 \%$ reduction in the incidence of tuberculosis over a 20 -year period, though 10-15 years after vaccination protection dropped to $59 \%$ and after this no valid comparison could be made because of the low incidence of disease in both test and control groups. ${ }^{1}$ Neither miliary tuberculosis nor tuberculous meningitis was seen in the test group whereas 10 cases occurred in the controls, and all other forms of tuberculous disease were reduced. ${ }^{2}$ More recent evidence suggests that from 1967 to 1976 the school BCG programme continued to offer more than $70 \%$ protection for at least 10 years. ${ }^{3}$ Neither study tried to assess how race or place of birth may modify this protection and, in view of the variation in protection-from zero to $80 \%$ -in BCG trials worldwide no extrapolations should be made.

Extensive experience has shown that BCG vaccination is one of the safest vaccinations, ${ }^{4}$ though complications at the site of injection include prolonged ulceration and subcutaneous abscess, and the draining lymph nodes occasionally suppurate. These complications occur more frequently in neonates and infants and are related to the dose and possibly to the strain used. Disseminated infection is rare.

The estimated total cost of a vaccination in the school programme at June 1975 prices was $99 \mathrm{p} .{ }^{5}$ This is not expensive, but even with favourable assumptions calculations showed that by the early 1980s the school programme would be four times more expensive than stopping vaccination and treating the resulting cases of tuberculosis. The difference in costs will increase further if recent advice about reducing the length of hospital stay is widely followed. ${ }^{6}$ Moreover, a consequence of BCG administration is tuberculin sensitivity for a variable period, and this devalues the later use of tuberculin testing both as an aid to individual diagnosis and as an epidemiological tool. It would also preclude the use of chemoprophylaxis on a scale as wide as that recommended in the United States. ${ }^{7}$

Thus BCG vaccination is safe, protective, and cheap, though the school programme does not pay its way financially. Who then should receive it? On the unproved assumption that the effectiveness of BCG in British schoolchildren will be mirrored in the general population, vaccination might reasonably continue to be offered to tuberculin-negative people in highrisk groups, including contacts and hospital and laboratory workers. We have long appreciated that the school programme has a limited lifespan in view of the decreasing incidence of tuberculosis, although pockets of relatively higher incidence remain. There were 6810 notifications of respiratory tuberculosis in England and Wales in 1979, a further decrease of $3.6 \%{ }^{8}$ For each 100000 BCG vaccinations given in the programme during 1979, an estimated 44 cases of notified tuberculosis will be prevented over the next 15 years. ${ }^{3}$ This is not the cheapest way of managing tuberculosis, but how can we price the value of a prevented case? Emotional decisions are inevitable, but the school programme could reasonably be stopped in areas of the country where the likelihood of contact with the disease is minimal.

As a report of an outbreak of tuberculosis in the West Midlands in 1979 shows, the use of the tuberculin test in children who have not yet received BCG vaccination combined with intensive contact tracing can define and help control an outbreak. ${ }^{9}$ Discussion of the role of BCG vaccination should not be allowed to detract from the emphasis placed on the diagnosis of patients with symptoms, the search for infected individuals without symptoms, and the effective treatment of both.

${ }^{1}$ Hart PD'A, Sutherland I. BCG and vole bacillus vaccines in the prevention of tuberculosis in adolescence and early adult life. Final report to the Medical Research Council. Br Med f 1977;ii:293-5.

2 Fourth report to the Medical Research Council by its tuberculosis vaccines clinical trials committee. BCG and vole bacillus vaccines in the prevention of tuberculosis in adolescence and early adult life. Bull WHO $1972 ; 46: 371-85$.

${ }^{3}$ A report from the research committee of the British Thoracic Association. Effectiveness of BCG vaccination in Great Britain in 1978. $\mathrm{Br} \mathcal{F} \mathrm{Dis}$ Chest (in press).

${ }^{4}$ ten Dam HG, Toman K, Hitze KL, Guld J. Present knowledge of immunization against tuberculosis. Bull WHO 1976;54:255-69.

5 Stilwell JA. Benefits and costs of the schools' BCG vaccination programme. Br Med F 1976; : 1002-4.

${ }^{6}$ Anonymous. Isolation of patients with pulmonary tuberculosis. $\mathrm{Br} \mathrm{Med} \mathcal{F}$ 1980;280:962-3.

7 American Thoracic Society. Preventive therapy of tuberculous infection. Am Rev Respir Dis 1974;110:371-4.

${ }^{8}$ Office of Population Censuses and Surveys. Deaths and corrected notifications of selected diseases. Office of Population Censuses and Surveys Monitor 1980;MB 2 80/2:3.

${ }^{9}$ Rao VR, Joanes RF, Kilbane P, Galbraith NS. Outbreak of tuberculosis after minimal exposure to infection. $\mathrm{Br} \mathrm{Med} \mathcal{F} 1980 ; 281: 187-9$. 